\title{
SUCCESSFUL TRANSFER OF A FERTILIZED BOVINE EGG BY NON-SURGICAL TECHNIQUES
}

\author{
T. SUGIE \\ National Institute of Animal Industry, Chiba, Japan \\ (Received 30th December 1964, revised 9th March 1965)
}

\begin{abstract}
Summary. Two fertilized eggs, recovered from two gonadotrophintreated Holstein heifers 4 and 6 days after ovulation, were transferred to the uteri of two synchronized recipient heifers by means of nonsurgical techniques. A specially designed apparatus was used for the transfer. Both recipients became pregnant and one gave birth to a normal bull calf after 268 days. It was established by blood-typing that the calf had developed from a transferred embryo. The other recipient aborted on the 80th day of pregnancy.
\end{abstract}

\section{INTRODUCTION}

The birth of calves following surgical egg transfer has been reported by Willett, Black, Casida, Stone \& Buckner (1951); Willett, Buckner \& Larson (1953), and Avery, Fahning, Pursel \& Graham (1962). But, in spite of much effort (Dowling, 1949; Willett, 1953; Dracy, 1953; Dziuk \& Petersen, 1954; Dziuk, Donker, Nichols \& Petersen, 1958) no success has yet been achieved in producing a calf by non-surgical egg transfer techniques, except one case reported recently by Mutter, Graden \& Olds (1964). It appears that one of the main causes of this failure is that any ova deposited into the uterine lumen via the cervix are soon expelled into the vagina, owing to constriction of the uterus arising from cervical stimulation (Shah, 1956; Bennett \& Rowson, 1961; Harper, Bennett \& Rowson, 1961 ; Rowson, Bennett \& Harper, 1964). Hafez \& Sugie (1961, 1963) transferred rabbit eggs non-surgically into the uteri of heifers by means of an apparatus designed to pass through the vaginal wall after insufflating the uterus with $\mathrm{CO}_{2}$ via the cervix. However, frequent failures were experienced in locating the uterine lumen and, in addition, cervical stimulation prior to $\mathrm{CO}_{2}$ insufflation led to an accelerated constriction of the uterus.

For this reason a new procedure was devised for the insufflation of $\mathrm{CO}_{2}$. The present paper describes the new non-surgical techniques for egg transfer in cattle and the birth of a live calf resulting from their application.

\section{MATERIALS AND METHODS}

Four Holstein heifers, whose live-weights ranged from 395 to $611 \mathrm{~kg}$ were used, two as donors and two as recipients. They were showing normal oestrous cycles. Two of the heifers (donors) were treated with gonadotrophins, PMS and HCG, to induce super-ovulation, as described by Hafez, Sugie \& Hunt (1963). They 
were inseminated artificially with semen from a fertile bull every day during the heat following gonadotrophin treatment. One donor was killed 4 days after ovulation had been detected by rectal palpation of the ovaries. Egg recovery was then carried out by flushing the fallopian tubes with physiological saline solution. In the case of the other donor, egg recovery was performed in vivo 6 days after ovulation, using the apparatus described by Rowson \& Dowling

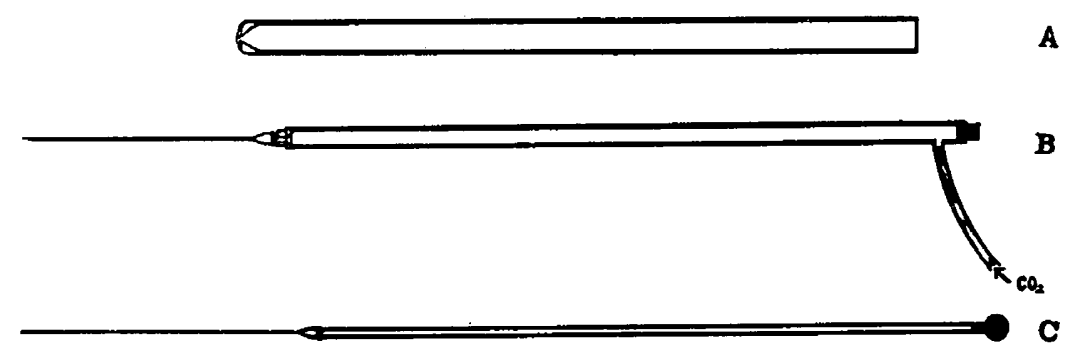

Text-Fig. 1. Diagram of apparatus for non-surgical egg transfer in cattle. One-sixth actual size.

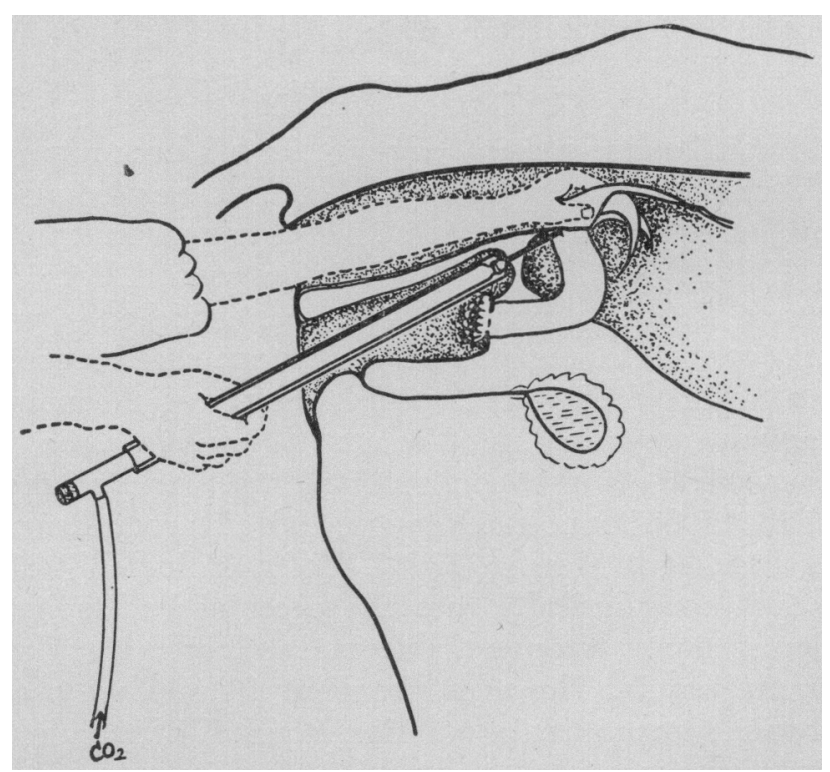

TEXT-FIG. 2. Diagram of non-surgical technique used to locate the uterine lumen in cattle.

(1949). Immediately after recovery, the eggs were transferred to tubes containing $2 \mathrm{ml}$ of autologous blood serum and Ringer's solution* $(1: 1)+1000$ i.u. penicillin $/ \mathrm{ml}$, and stored at $35^{\circ} \mathrm{C}$ for 2 to $3 \mathrm{hr}$ until required for transfer. The following specially designed apparatus was used to transfer single eggs to the distal end of the uterine horn of two recipients, in which oestrus had occurred at the same time as, or 1 day later than, in the donors.

* Sodium chloride $8.6 \mathrm{~g}$, potassium chloride $0.3 \mathrm{~g}$, calcium chloride $0.33 \mathrm{~g}$, distilled water $1000 \mathrm{ml}$. 
The apparatus consists of three plastic tubes, A, B and c, which fit one inside the other, as shown in Text-fig. 1 and Pl. 1, Fig. 1. The outer tube (A) surrounding the middle tube (B) leads the latter to the anterior fornix of the vagina. The middle tube is attached to a long hypodermic needle with a sharp tip, which is passed through the vaginal wall at the fornix, by-passing the cervix into the uterine lumen by manual guidance per rectum (see Text-fig. 2). In addition, it has a cock on the opposite end to take in $\mathrm{CO}_{2}$ gas. The purpose of the middle tube is to aid location of the uterine lumen by insufflation of $\mathrm{CO}_{2}$ from the needle tip, and to guide the inner tube (c) into the uterine lumen (see Text-fig. 3). The inner tube, in which the eggs are transferred, is fitted with a hypodermic needle with a blunt tip, which is passed through the first needle, into the uterine lumen.

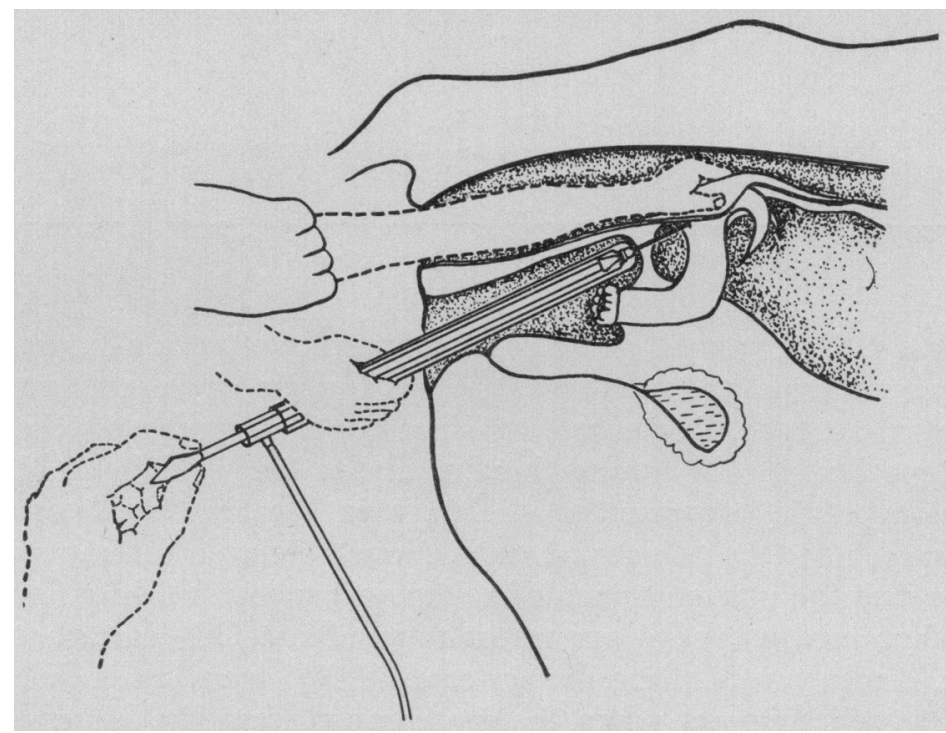

TeXT-FIG. 3. Diagram of non-surgical technique used for egg transfer in cattle.

The eggs were sucked into the needle attached to the inner tube which was passed through the middle tube and guided into the uterine lumen of the recipient heifers. Then the eggs were expelled into the uterine cavity by slight pressure on the rubber bulb at the opposite end of tube c (see Text-fig. 3).

The determinative test for blood typing was carried out using forty reagents to identify the true parents of the calf produced by one of the recipient heifers.

\section{RESULTS}

One 8-cell egg and two 1-cell eggs were recovered from the fallopian tubes of the donor killed 4 days after ovulation whilst one 32-cell egg was recovered in vivo from the second donor. The recipient of the more advanced morula, produced a normal bull calf, weighing $41.5 \mathrm{~kg}$, on 6th August 1964, 268 days after transfer (see Pl. 1, Fig. 2). In the other recipient, in which oestrus occurred on the same day as in the donor, pregnancy was confirmed by the blastodermic vesicle test per rectum on the 46 th, 55th, 63rd and 74 th days after transfer. 
Abortion occurred on the 80th day of pregnancy-its cause is not known. The results of the blood-typing examination are shown in Table 1.

It was shown conclusively by the responses in the $\mathrm{B}, \mathrm{C}$ and $\mathrm{Z}$ blood group systems that the calf had received its blood type from the sire and the egg donor. Further, responses in all of the systems tested revealed that the host mother had not contributed to the calf's blood type.

TABLE 1

DETERMINATION OF BLOOD TYPING

\begin{tabular}{l|c|c|c|c|c|c|c}
\hline \multirow{3}{*}{ Animals } & \multicolumn{7}{|c}{ Blood group systems } \\
\cline { 2 - 8 } & $A$ & $B$ & $C$ & $F V$ & $S U$ & $M$ & $Z$ \\
\hline Calf & $\mathrm{A} /-$ & $\mathrm{GY}_{2} / \mathrm{O}_{2}$ & $\mathrm{~W} /-$ & $\mathrm{F} / \mathrm{F}$ & $-/-$ & $-/-$ & $\mathrm{Z} /-$ \\
Sire & $-/-$ & $\mathrm{O}_{1} / \mathrm{Y}_{2}$ & $\mathrm{X}_{2} /-$ & $\mathrm{F} / \mathrm{F}$ & $\mathrm{H}^{\prime} /-$ & $\mathrm{M}_{2} /-$ & $\mathrm{Z} / \mathrm{Z}$ \\
Donor & $\mathrm{A} /-$ & $\mathrm{GY}_{2} / \mathrm{E}_{2}^{\prime}$ & $\mathrm{C} / \mathrm{W}$ & $\mathrm{F} / \mathrm{F}$ & $-/-$ & $\mathrm{M}_{2} /-$ & $-/-$ \\
Recipient & $\mathrm{A} /$ & $\mathrm{BQD}^{\prime} \mathrm{K}^{\prime} 2$ & $\mathrm{R} /$ & $\mathrm{F} / \mathrm{F}$ & $\mathrm{H}^{\prime} /-$ & $\mathrm{M}_{2} /-$ & $\mathrm{Z} / \mathrm{Z}$ \\
\hline
\end{tabular}

\section{DISCUSSION}

Avery et al. (1962) reported an attempt to transfer eggs non-surgically to the uterus of cows through the rectal wall using a hypodermic needle attached to a long polyethylene tube. However, it was not established whether the eggs were actually deposited in the uterine lumen. Hafez \& Sugie (1961, 1963), also working with cattle, experienced difficulty in locating the uterine lumen, which was occluded in its natural state. None of eleven attempts to transfer rabbit eggs into the uterine lumen of heifers was successful. In a further series, in which they used a special apparatus to insufflate $\mathrm{CO}_{2}$ into the lumen via the cervix, eleven out of twenty-seven cases $(41 \%)$ were successful. However, failures were still frequent when the gas escaped from the lumen due to the heifers straining. There was also the added complication of uterine constriction induced by cervical stimulation.

In the present successful experiments, $\mathrm{CO}_{2}$ was insufflated into the uterine lumen without stimulating the cervix which was by-passed. Preliminary tests had shown this technique was better suited to location of the lumen than was the previous one. Success in transferring rabbit eggs to the uterus of cows was obtained in eight out of twelve attempts $(67 \%)$ with less gas. In addition, the time taken in transferring the eggs was considerably shortened by the new procedures. By rectal palpation the operator could definitely feel the gas passing into the uterine lumen.

The technique did not interfere with conception in the recipients. In a preliminary experiment, involving eight goats, four out of five recipients produced five kids following the transfer of two eggs to each recipient's uterus, using the same apparatus with surgery.

On the basis of these results it is suggested that this new non-surgical technique holds promise for the practical application of egg transfer in cattle. At the same time it is recognized that the present observations require to be extended. 


\section{PLATE 1}
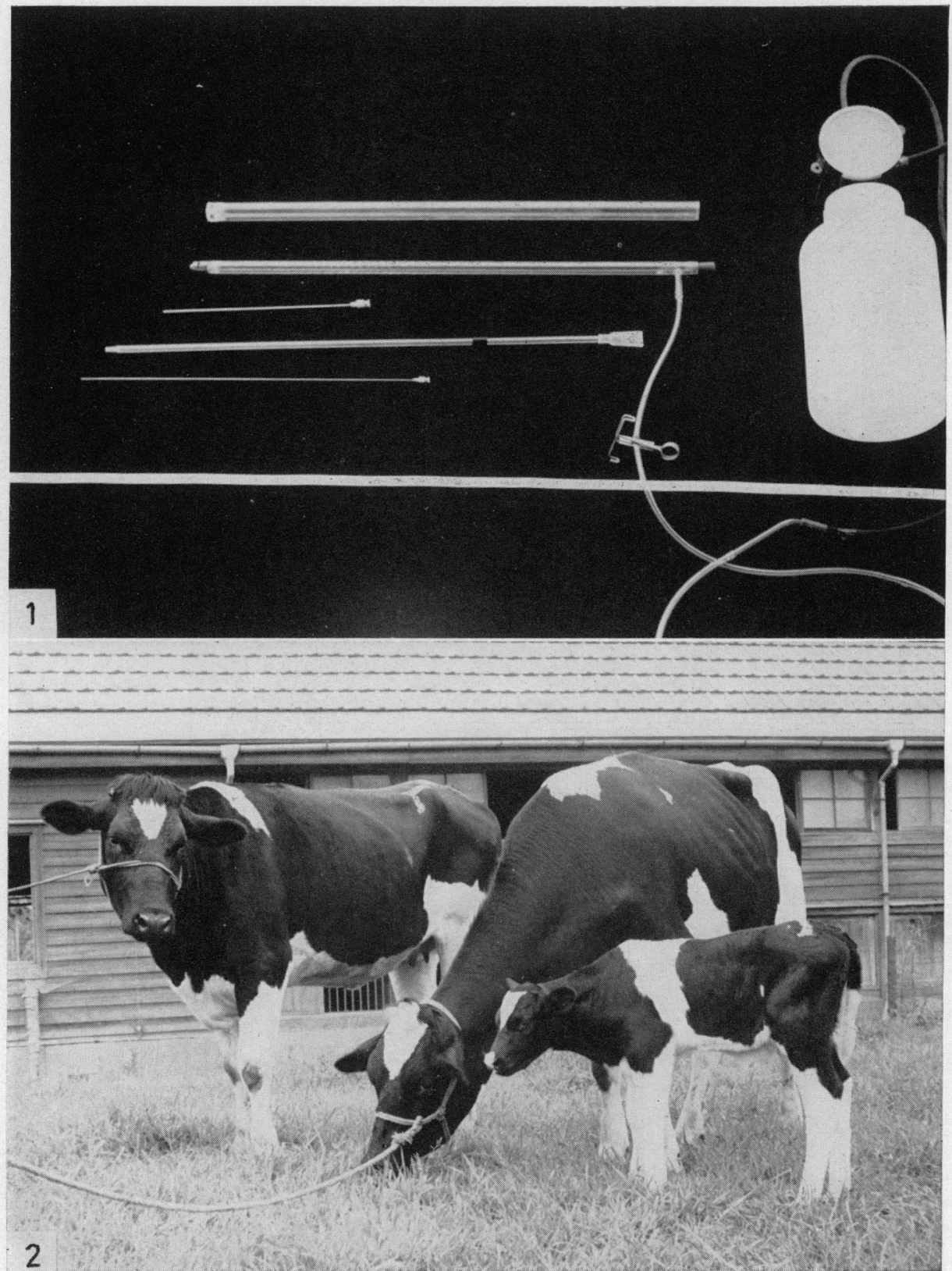

Fic. 1. Apparatus used for egg transfer in the cow.

Fic. 2. The calf produced from the transfer of a 32-cell egg by non-surgical techniques. From the left: donor, recipient and calf.

(Facing p. 200) 
The author would like to express his deep appreciation to Professor Dr Y. Nishikawa of Kyoto University, Japan, and Dr E. S. E. Hafez of Washington State University, U.S.A., for their advice. Thanks are also due to Mr T. Soma, $\mathrm{Dr} \mathrm{H}$. Onuma and $\mathrm{Mr} \mathrm{K}$. Ostuki for their technical assistance. In addition, the determination of blood typing was carried out by $\mathrm{Dr} \mathrm{T}$. Hosoda and $\mathrm{Mr} \mathrm{K}$. Mogi of the Serological Laboratory in this Institute, for which the author is deeply grateful.

\section{REFERENCES}

Avery, T. L., Fahning, M. L., Purser, V. G. \& Graham, E. F. (1962) Investigations associated with the transplantation of bovine ova. IV. Transplantation of ova. F. Reprod. Fertil. 3, 229.

Bennett, J. P. \& Rowson, L. E. A. (1961) The use of radioactive artificial eggs in studies of egg transfer and transport in the female reproductive tract. Proc. 4th int. Congr. Anim. Reprod. 2, 360.

Dowling, D. F. (1949) Problems of the transplantation of fertilized ova. F. agric. Sci. 39, 374.

Dracy, A. E. (1953) The future of ova transfer. Iowa State Coll. 7. Sci. 28, 101.

Dziuk, P. J., Donker, J. D., Nichols, J. R. \& Petersen, W. E. (1958) Problems associated with the transfer of ova between cattle. Minn. agric. Exp. Sta. Tech. Bull. 222.

Dziuk, P. J. \& Petersen, W. E. (1954) Attempts at non-surgical transfer of bovine ova. F. Anim. Sci. 13,1019 .

Hafez, E. S. E. \& Sugie, T. (1961) Superovulatory responses in beef cattle and an experimental approach for non-surgical ova transfer. Proc. 4 th int. Congr. Anim. Reprod. 2, 387.

HAfez, E. S. E. \& SugIE, T. (1963) Reciprocal transfer of cattle and rabbit embryos. F. Anim. Sci. 22,30 .

Hafez, E. S. E., Sugre, T. \& Hunt, W. L. (1963) Superovulation and related phenomena in the beef cow. II. Effect of oestrogen administration on production of ova. 7. Reprod. Fertil. 5, 381.

Harper, M. J. K., Bennett, J. P. \& Rowson, L. E. A. (1961) Movement of the ovum in the reproductive tract. A possible explanation for the failure of non-surgical ovum transfers in the cow. Nature, Lond. 190, 789.

Mutter, L. R., Graden, A. P. \& Olds, D. (1964) Successful non-surgical bovine embryo transfer. A. I. Digest, 12, 3 .

Rowson, L. E. A., BenNett, J. P. \& HARPer, M. J. K. (1964) The problem of non-surgical egg transfer to the cow uterus. Vet. Rec. 76, 21.

Rowson, L. E. A. \& Dowling, D. F. (1949) An apparatus for the extraction of fertilized eggs from the living cow. Vet. Rec. 61, 191.

SHAH, M. K. (1956) Reciprocal egg transplantations to study the embryo uterine relationship in heat induced failure of pregnancy in rabbit. Nature, Lond. 177, 1134.

WiLLETT, E. L. (1953) Egg transfer and superovulation in farm animals. Iowa State Coll. 7. Sci. 28, 83.

Willett, E. L., Black, W. G., Casida, L. E., Stone, W. H. \& Buckner, P. J. (1951) Successful transplantation of a fertilized bovine ovum. Science, 113, 247.

Willett, E. L., BuckNer, P. J. \& LARson, G. L. (1953) Three successful transplantations of fertilized bovine eggs. 7. Dairy Sci. 36, 520. 